\title{
Mitmachen und gewinnen
}

\section{Sichern Sie sich Ihren Preis! So einfach geht es: Lösen Sie das Kreuzworträtsel auf Seite 73 und schicken Sie das Lösungswort bis zum 17. Dezember an die Redaktion HEILBERUFE.}

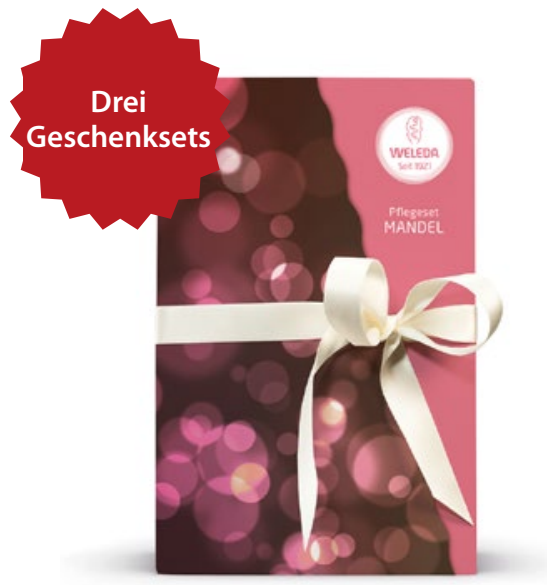

\section{1.-3. Preis}

\section{Natürlich pflegen}

- Die neuen Weihnachts-Geschenksets von Weleda stehen ganz im Zeichen von Nachtkerze, Granatapfel, Sanddorn, Wildrose und Mandel - edle Pflanzen, die die Wirkstoffe für ein seidig-weiches Hautgefühl spenden. Die ph-neutrale und seifenfreie Formulierung der Mandel Sensitiv Pflegedusche wirkt rückfettend und schützt sensible Haut vor unnötigen Reizen. Die Mandel Sensitiv Pflegelotion versorgt die Haut nachhaltig mit Feuchtigkeit, mildert auf diese Weise Reize und entspannt die Haut. Die Komposition mit kostbarem BioMandelöl und Bienenwachs zieht schnell ein und fördert das natürliche Gleichgewicht der Haut. Wirksamkeit und Verträglichkeit der Mandel Sensitiv Pflegeprodukte wurden dermatologisch getestet und bestätigt. Wir verlosen drei Mandel-Geschenksets.

www.weleda.de

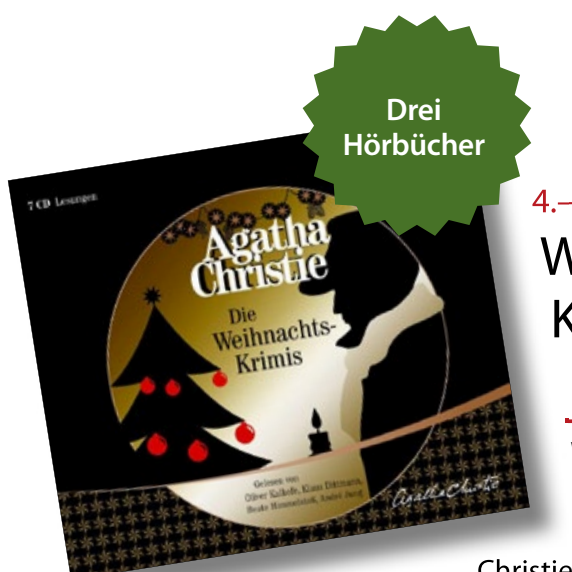

4.-6. Preis

\section{Weihnachts- Krimis}

—Was ist das Schönste an Weihnachten? Kaltblütige Morde und raffinierte Verbrechen von Agatha Christie natürlich. Denn Miss Marple und Hercule Poirot erzählen vor wohligem Kaminfeuer ihre alten Fälle und Harley Quin scheut nicht Wind und Wetter, um einen fast verjährten Mord aufzuklären. Dass Weihnachten nicht beschaulich sein wird, sondern einen grausamen Mord beschert, kommt Hercule Poirot und seinen kleinen grauen Zellen gerade recht. Lauschen Sie den Stimmen von Oliver Kalkofe, Klaus Dittmann, Beate Himmelstoß und André Jung, die die zeitlosen Krimis von Agatha Christie mit Witz, Charme und Spannung lesen.

Agatha Christie. Die Weihnachts-Krimis. Der Hörverlag 2012. ISBN 978-3-86717-903-4; € 19,99 www.randomhouse.de/ hoerverlag

\section{Preis \\ Kongress Pflege 2016}

_ Am 22. und 23. Januar 2016 findet im Berliner Hotel Maritim proArte der Kongress Pflege 2016 statt. Seit zwei Jahrzehnten ist dieser Kongress ein Pflichttermin im Fortbildungskalender für Pflegende. Aktuell, nachhaltig und praxis-

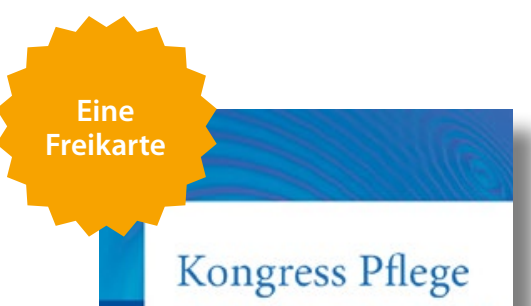

Kongress Pflege Berlin | 22. - 23.01.2016

\section{Springer Medizin}

relevant: Neben der Fachfortbildung ist der Kongress von Springer Medizin eine optimale Plattform für Networking und professionellen Austausch. Es geht um Themen wie Patientenrechtegesetz, pflegerische Sterbebegleitung, Pflegestärkungsgesetze oder Vorsorgevollmacht. Wenn auch Sie im Januar in Berlin dabei sein wollen: Wir verlosen eine Freikarte zur Teilnahme am Kongress Pflege 2016, inklusive der festlichen Abendveranstaltung.

www.gesundheitskongresse.de

ADIPOSITAS lautete das Lösungswort in der Oktober-Ausgabe.

Gewonnen haben:

J. Blaich, B. Roth, B. Eckhoff, M. Kleibrink, J. Zielinski,

G. Schreiter, P. Glintschert

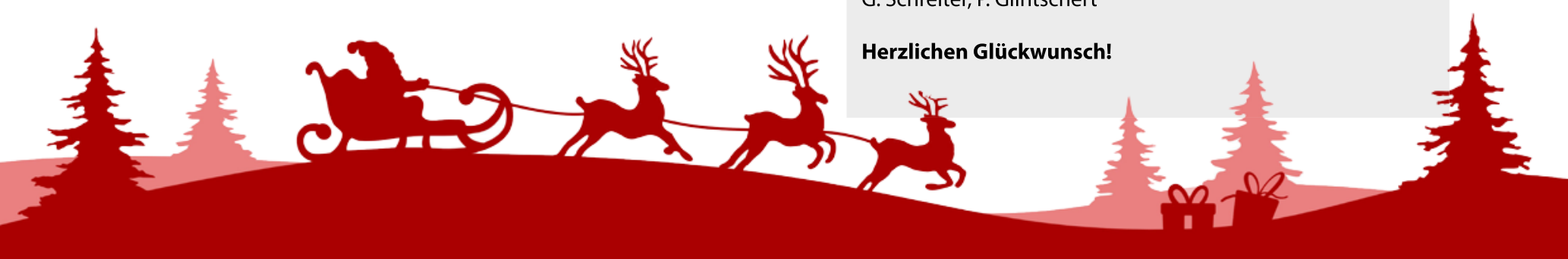

